DOI: http://doi.org/10.52716/jprs.v11i4.559

\title{
Synthesis of Hematite Nano Material and Its Effect on Properties of Water Based Drilling Mud
}

\author{
Narjis Mohmmad Ahmed ${ }^{1, *}$, Dr. Hassan Abdul Hadi Abdul Hussein², Mustafa H. \\ Flayyih $^{3}$ \\ ${ }^{1,2}$ University of Baghdad, Iraq, College of Engineering, Department of Petroleum \\ ${ }^{3}$ Ministry of Oil/ Petroleum Research and Development Center \\ 1," Corresponding Author E-mail: anarjissmohmmed@yahoo.com
}

Received 23/2/2021, Accepted 27/7/2021, Published 20/12/2021

This work is licensed under a Creative Commons Attribution 4.0 International License.

\begin{abstract}
$\underline{\text { Abstract }}$
The worldwide use of nanotechnology in most industries, such as in oil and gas industries, the world now has been directed towards introducing this modern technology in drilling fluids for the purpose of reaching and extracting hydrocarbons that exist at high depth where high temperatures and high pressure present using this technology to achieve the required mud properties with lowest cost.

In this research, the particles of Nano hematite were prepared in laboratory using two methods, the first method by chemical reaction between iron nitrate $\left(\mathrm{Fe}\left(\mathrm{NO}_{3}\right)_{3} \bullet 9 \mathrm{H}_{2} \mathrm{O}\right)$ and ammonium hydroxide $(\mathrm{NH} 4 \mathrm{OH})$, after that, prepared Nano-materials were subjected to AFM, XRD testing in order to investigate the size and type of particles, the investigations showed that the formed particles were $\mathrm{Fe}_{2} \mathrm{O}_{3}(<100 \mathrm{~nm})$. The second method is similar to the first method except adding (CTAB) material in order to reduce the interfacial tension leading to $4.5 \mathrm{~nm}$ Nano-material. Three samples of drilling mud were prepared, the first sample was prepared from water and bentonite only, the second sample was prepared from water, bentonite and nano (prepared from first method), the third samples was prepared from water, bentonite and nano (prepared from second method), rheological properties, filtration, density, lubricity, sagging and magnetism properties were measured by analyzing and comparing the results. The results were obtained showed that the small effect of nano material filtration, density, lubricity, and sagging properties, except the viscosity increase when the second sample of Nano hematite was added to the mud prepared from water and bentonite. Also, the magnetism increase when the second sample of nano hematite was added to the mud prepared from water and bentonite, due to the difference in the molecular arrangement caused by the presence of CTAB.
\end{abstract}


Key words: Drilling fluid; Rheology; Mud additives; Well bore.

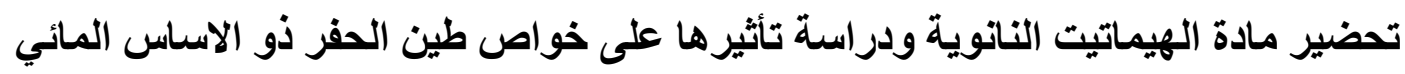

الخلاصة:

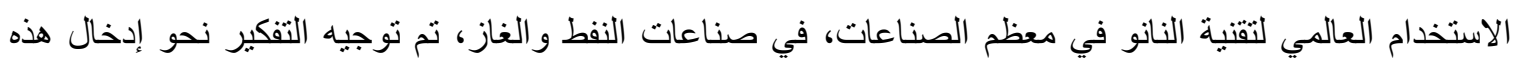

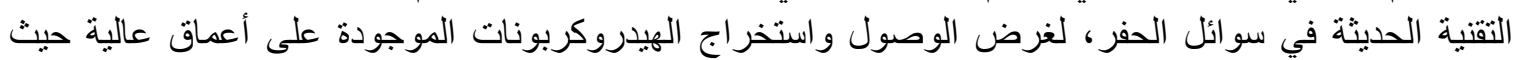

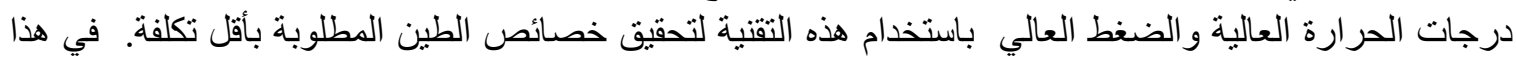

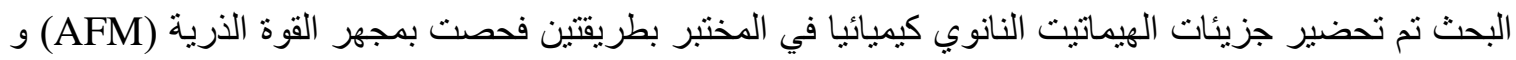

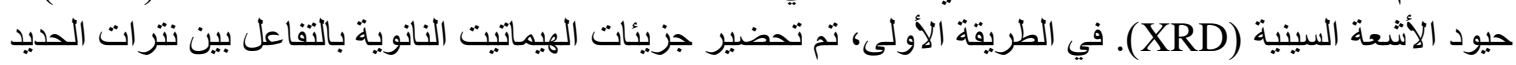

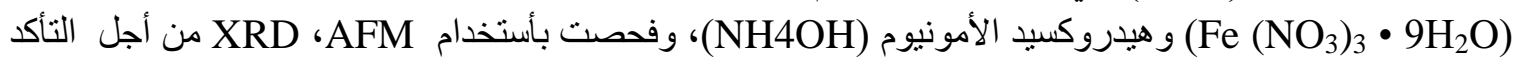
من حجم ونوع الجسيمات، مما أظهر أن الجسيمات المتكونة كانت

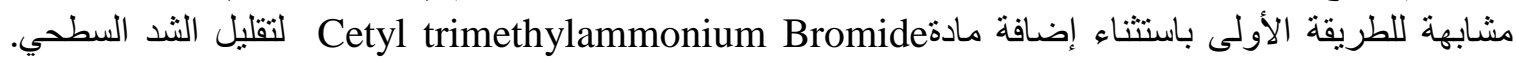

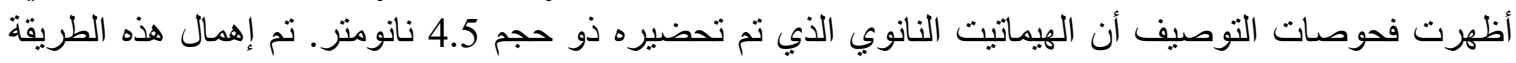

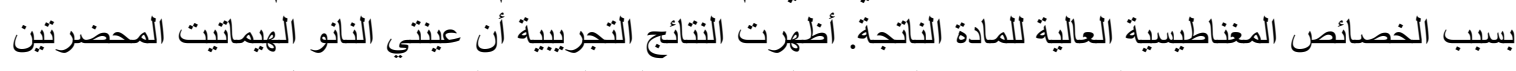

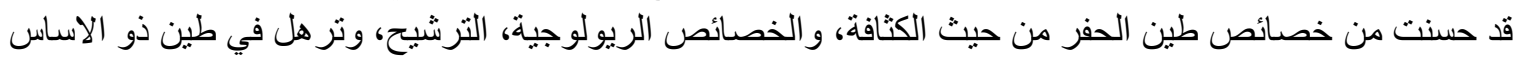
المائي.

\section{Introduction}

During well drilling operation, mud engineer needed to add weighting material to the drilling fluid for different purposes to works optimally. These weighting materials were formulated taking into account several aspects. Among these aspects is the environmental one, where the drilling fluid used must be composed of a material that does not affect in the environment outside and inside the well, and easy to handle and use this material. In addition, the most important aspect is the economic aspect where the material must be economically feasible, which have the lowest cost and give best result. [1]

Despite its many advantages, barite has some problems, such as the sag phenomenon, which is the problem of drilling fluid made from barite, when the weighting material (calcium carbonate, barite, etc.) is separated from the liquid phase and settles down. Barite sagging may lead to large differences in the density of drilling mud in the well bore. Light density at the top and heavy density at the bottom, in the vertical wells. Barite sag occurs when circulation of drilling fluid stops, while in deviated wells. Heavier particles settle on the lower wellbore side and lighter fluid types on the higher sides. In 
addition, Demand exceeds production of barite. Hence, it is necessary to define alternative weighting materials. [2]

Compared to barite, hematite has many advantages such as higher specific gravity, greater solubility in acidic media, and a lower rate of depletion in general due to its hardness. One of the main claims hematite as an improvement over barite, It is also considered an abundant material, in addition to that it has a higher specific gravity of 4.90to $5.30 \mathrm{~g} / \mathrm{cm} 3$ [3] then, the drilling companies can use less amount of hematite in drilling fluid than barite, and achieve the same results. These results lead to decreasing in the cost of weight material, and fewer solid particles dispersed in the mud. Additionally, hematite is a good choice for drilling applications [4] because it is incredibly pure and free of contaminants. Moreover, better performance in terms of reduced need for dilution, improved penetration rate, and increased solids tolerance $g$ are other qualities associated with hematite as a weighting agent for drilling applications. [5]

The main goal of the proposed study is to synthesize and characterize of hematite nanoparticles experimentally by two methods. Then the synthesized materials were used as additives in drilling fluid in order to investigate their influences on weighting, and Comparison of density, rheological, filtration of drilling fluid properties, magnetic and lubricity test between Nano hematite (NHL1) and (NHL2).

\section{Research Methodology and Experimental Procedure}

\subsection{Materials}

Many chemical materials used in this work, Table (1) summarize the materials that have been used in this study are: 
Table (1) Specifications of Some Materials That Were Used During Experimental Work

\begin{tabular}{|c|c|c|}
\hline Name & $\underline{\text { Formula }}$ & $\underline{\text { Appearance }}$ \\
\hline Bentonite & - & Gree powder \\
\hline $\begin{array}{c}\text { Hematite iron oxide Nano } \\
\text { partical (100nm) }\end{array}$ & Fe2O3 & Nutty red powder \\
\hline $\begin{array}{c}\text { Hematite iron oxide Nano } \\
\text { partical (5nm) }\end{array}$ & Fe2O3 & Nutty red powder \\
\hline Triple iron nitrate & Fe (NO3)3.9H2O & Silver powder \\
\hline Ammonium hydroxide & NH4OH & Transparent liquid \\
\hline CTAB & C19H42BrN & white powder \\
\hline
\end{tabular}

\section{Bentonite}

The commercial type of Bentonite was used, provide it by Pdf Company.

\section{Hematite}

Hematite nanoparticles were obtained by preparing it in the laboratory through a chemical reaction in two ways.

Triple iron nitrate Fe (NO3)3.9H2O

The commercial type of iron nitrate is use, the purpose of the chemical manufacturing process of Nano hematite.

\section{Ammonium hydroxide $\mathrm{NH4OH}$}

A commercial type of ammonium hydroxide, with a concentration of $25 \%$ ammonium, is use to complete the chemical reaction process for manufacturing of hematite nanoparticles.

\section{Cetyltrimethylammonium Bromide (CTAB)}

It has been used in synthesis of Hematite nanoparticles, 
The experimental work was carried out in Tehran (Pars Drilling Fluid lab).by using the following the following tools:

\subsection{Nanoparticle Analysis}

Many characterization techniques were used in present work such as XRD-7000 X-ray Diffractometer, Atomic force microscope (AFM).

\subsection{Drilling Fluid Tests}

The experimental work was carried out at Pars Drilling Fluid (PDF) in Tehran. It is necessary to measure the properties of drilling fluid after preparation, and the tests were performed on drilling fluids that were prepared using the following tools:

Drilling Fluid Mixer (Multi-Mixer) was used to mix drilling fluid to prepare for the clay material lab tests. The 5-axis multiple mixers have been fitted with the impeller blades. Every mandrel is equipped with one single sine wave impeller of approx. $25 \mathrm{~mm}$ in the diameter with flashing side up. That mixer is conforming to the API specifications 13-A which states that all the spindles are rotated at 11,500rpm +/- 300rpm. The mixer may be utilized for the mixing of the oil drilling fluids, water-based drilling fluids, and oil well cement. [12]

The water bath was used to incubate the samples in water at a constant temperature of $87^{\circ} \mathrm{C}$ over a long period of time, after selecting the temperature required for heating.

Mud Balance was used to weight the mud with a four-gauge clay scale to determine density or weight of drilling fluids. The clay scale has been designed with the clay cup at one end of an arm Fixed counterweight, which is balanced at opposite end, with the sliding Contestant weight is free for moving along a sliding scale. The level bubble has been mounted on a beam for ensuring the precise balance. On the front there are scales that range from 6.5 to $23 \mathrm{lbf}$.

The specific gravity is from $0.79 \mathrm{~g} / \mathrm{cc}$ to $2.72 \mathrm{~g} / \mathrm{cc}$. On the back side there are scales for 49 - 172 pounds / cubic feet and 340 - 1190 pounds per square inch / 1,000 feet. 
The static sag of the drilling fluid was measured using a mud balance at different temperatures $(25,35,65,85)$, as it expresses the sag that occurs to the mud over time and at higher temperatures.

OFITE's Lubricity and EP Tester is one of the high-quality instruments, it is utilized for measuring the drilling fluids' quality of lubrication, present the data for the assessment of the amount and the type of the added lubricant, which can be necessary, and for the prediction of wear rates of the mechanical parts in the common fluid systems. The most common lubricant test measurements fluid resistance to a variety of the additive Lubrications. For the standard test of lubrication coefficient, 150 pounds of the force (which correspond to 5000 - 10000 pound/inch ${ }^{2}$ of the pressure on the liquid intermediate) is applied between 2 hardened surfaces of the steel, a block, and a ring, rotating at $60 \mathrm{rpm} .^{[13]}$

API Filter Press the design of the OFITE low pressure filter press includes a cell body which is used for holding the sample of the mud, filter paper, a base cap with screen, and pressure inlet. Which is suited for the lab as well as field uses, those units became the standard of industry for the low temperature/low pressure filtration test.

Magnetic test instrument Magnetic susceptibility is the degree to which a substance can be attracted when placed in an external magnetic field. It is the ratio of the induced magnetization to the magnetic force of the induced field. In this study, a magnetic tool was used to apply an external magnetic force, to generate an induced force for the magnetizing materials. And examine the susceptibility of these materials to attraction when exposed to the same forces.

\subsection{Preparation of Nano hematite}

Hematite nanoparticles are preparing in laboratory by chemical reaction (from two methods):

\subsubsection{First method}

The chemical reaction between iron nitrate $\mathrm{Fe}(\mathrm{NO} 3) 3.9 \mathrm{H} 2 \mathrm{O}$ and Ammonium hydroxide $\mathrm{NH} 4 \mathrm{OH}$ with use nitric acid to conduct the reaction at $\mathrm{PH}=7$. [11]

$\mathrm{Fe}(\mathrm{NO3}) 3.9 \mathrm{H} 2 \mathrm{O}+\mathrm{NH} 4 \mathrm{OH} \longrightarrow \mathrm{Fe} 2 \mathrm{O3}$ 
Open Access

1- Weight 101 grams of iron nitrate.

2- Add iron nitrate to distilled water gradually, until the volume of (water + dissolved iron nitrate) reach to $250 \mathrm{~mm}$.

3- Place $85 \mathrm{~mm}$ of ammonium hydroxide in another flask.

4- Start the reaction (drop by drop) by fixing two containers, as shown in Figure (1), and starting distillation, distillation inside a cylinder that containing distilled water.

5- $\mathrm{PH}$ is measure continuously, until it does not exceed 8 , when that exceeds this value we add some drops of nitric acid to equalize PH again.

6- After end reaction, noticed that the product is hematite + ammonium nitrite + water.

7- The result of reaction is Leave for 24 hours.
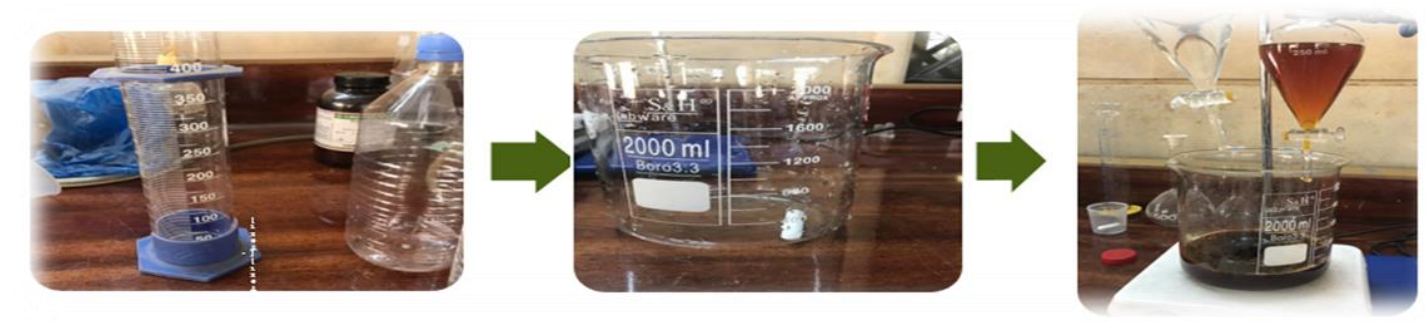

Fig. (1) Equipment and method of installing the system used

8- After 24 hours, noticed the water is up and the sediment is down.

9- Filter the material by using the filter paper (medium size (102) Pore Size) to separate the water from the precipitate.

10- After that, take the precipitate and wash it with distilled water, to get rid of suspended impurities and ammonium nitrite.

11- After that, wash it again. 

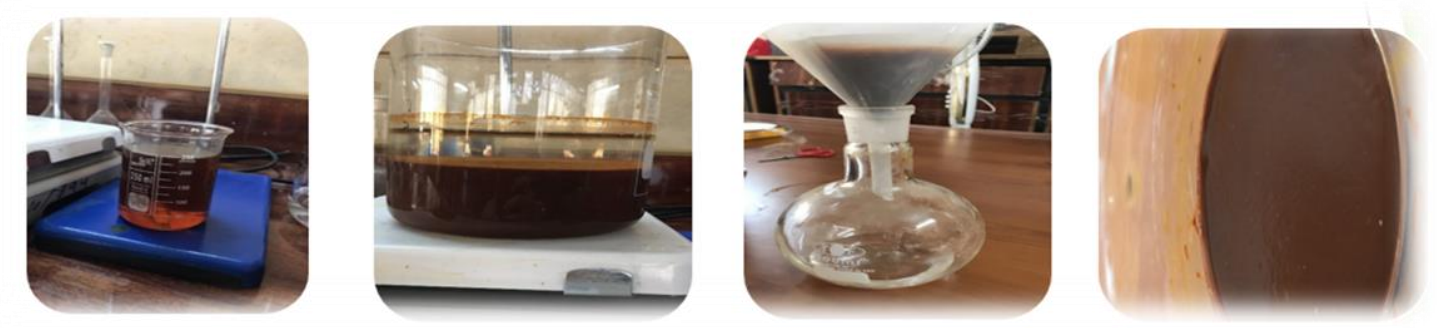

Fig. (2) Filter the material after leaving it for 24 hours at room temperature

12- Then the material put in a glass dish for drying, and place in a drying oven for a sex hours at $70^{\circ} \mathrm{C}$.

13- After drying the material place in Calcination at $450{ }^{\circ} \mathrm{C}$ for 5 hours.

14- Finally, grind it to convert it into powder so that, the sample is ready for testing.

The cost of reaction materials for the first method is 6 \$ to prepare $18 \mathrm{~g}$ of Nano hematite.
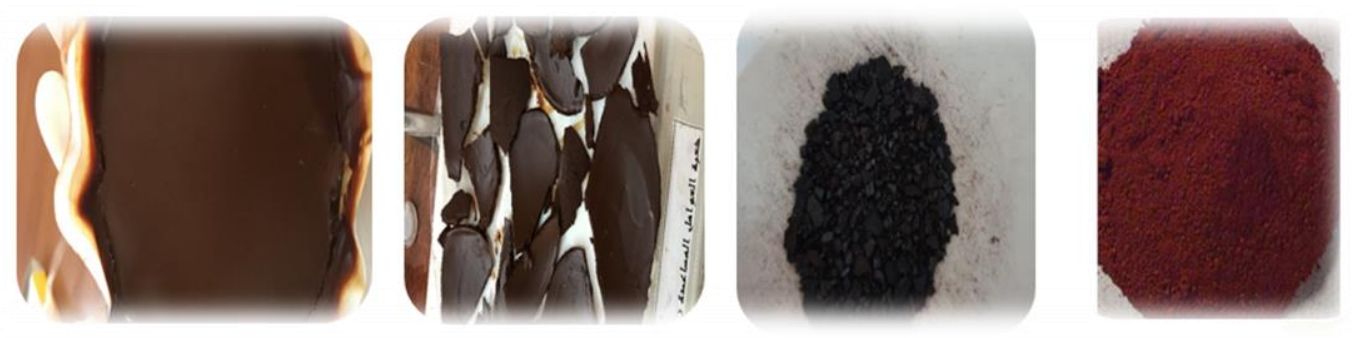

Fig. (3) Dried and calcinied and grinded at $450{ }^{\circ} \mathrm{C}$.

\subsubsection{The second method}

The same materials used in the first method, are using again at the same concentrations, with add a new substance, C19H42BrN (CTAB), by adding it and mixing with water.

$\mathrm{Fe}(\mathrm{NO3}) 3.9 \mathrm{H} 2 \mathrm{O}+\mathrm{NH} 4 \mathrm{OH}+\mathrm{C19H42BrN} \longrightarrow \mathrm{Fe} 2 \mathrm{O3} \ldots . . . \ldots . . .(2)$

- $\quad 3.6 \mathrm{~g}$ of CTAB is taking and dissolve in $500 \mathrm{ml}$ of water.

- $\quad$ After that, repeat the same distillation process and continues with the same steps.

Occurrence of foaming, and a change in the density and viscosity of the water when add the CTAB. [6] 
Open Access

No. 33, December 2021, pp.17-35

The cost of the reaction materials for the first method is $12 \$$ to prepare $18 \mathrm{~g}$ of Nano hematite.

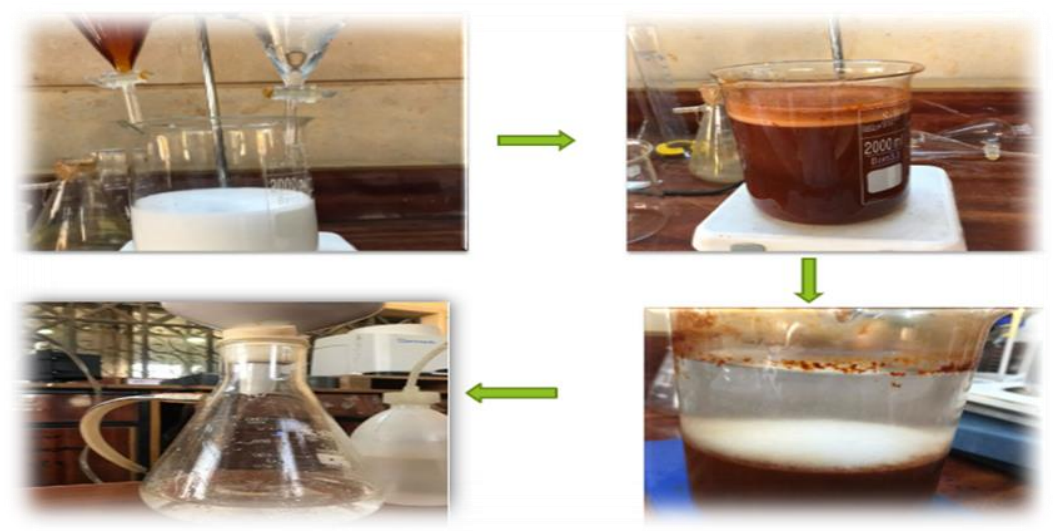

Fig. (4) Prepare the second sample by using CTAB
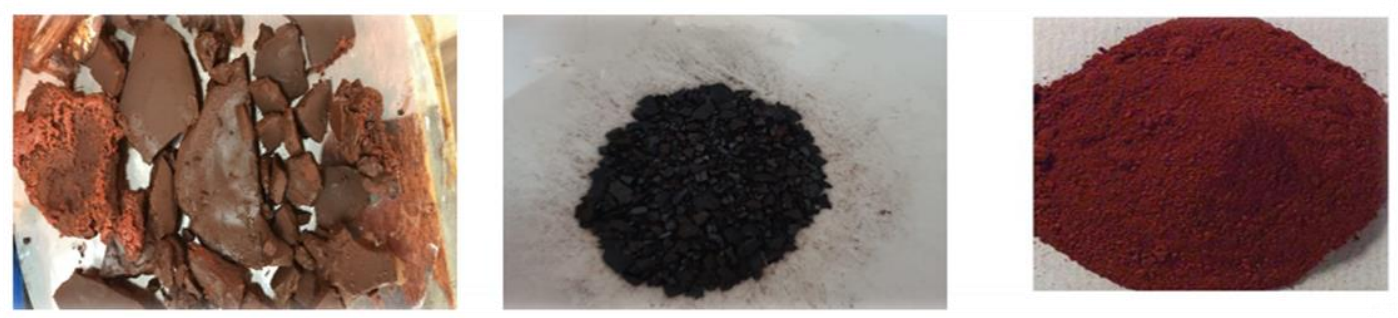

Fig. (5) Dried and calcinied and grinded at $450{ }^{\circ} \mathrm{C}$

\subsection{Drilling Fluid Preparation}

The drilling mud was prepared as follows:

1. Measure $350 \mathrm{cc}$ of water for 3 cups.

2. Weigh $18 \mathrm{~g}$ for each material that use as additive.

3. Each nanomaterial is mix alone with water for 5 minutes before adding bentonite to it, in order to ensure mixed well.

4. 22.5g of bentonite added to each Nanomaterial during mixing gradually, and mixed for 20 minutes.

*The barite materials add gradually to mud (during mix water with bentonite after 10 minutes of mixing time) and then mixing for 20 minutes.

5. The prepare samples are place in a water bath at $25^{\circ} \mathrm{C}$ for 24 hours.

6. All tests are performing for each sample.

7. Compare the results for each mud at the same concentrations. 


\section{Result and Discussion}

\subsection{Characterization of Prepared Nano hematite Particles}

Characterization of the lab prepared Nano hematite particles with two chemical methods were performed by the following methods:

\subsubsection{Atomic Force Microscope (AFM)}

Particle size distribution for both prepared Samples of Nano hematite was tested by AFM test. Figure (6) shows the histogram of size distribution of the first sample. The first model is Nano, most of the particles size ranged between (10 to 90) $\mathrm{nm}$. In addition, some of particles exceed the size of Nano scale ranged from (110 to 190) nm, the average size of particles of this sample is $99 \mathrm{~nm}$, which indicate that the model is Nano. [14]

The second sample, the same materials were used in preparation of the first model, but with the addition a new substance, CTAB, the effectiveness of this substance is reducing surface tension leading to a smaller particle size, as it has major role in the synthesis of nanoparticles. [7] [8].

The tests shows the success of this material in the synthesis of nanoparticles, the particle size range from (1 to 4.5) $\mathrm{nm}$ of the second model shown in Figure (6), which is considered a great success in synthesis of the nanoparticles.
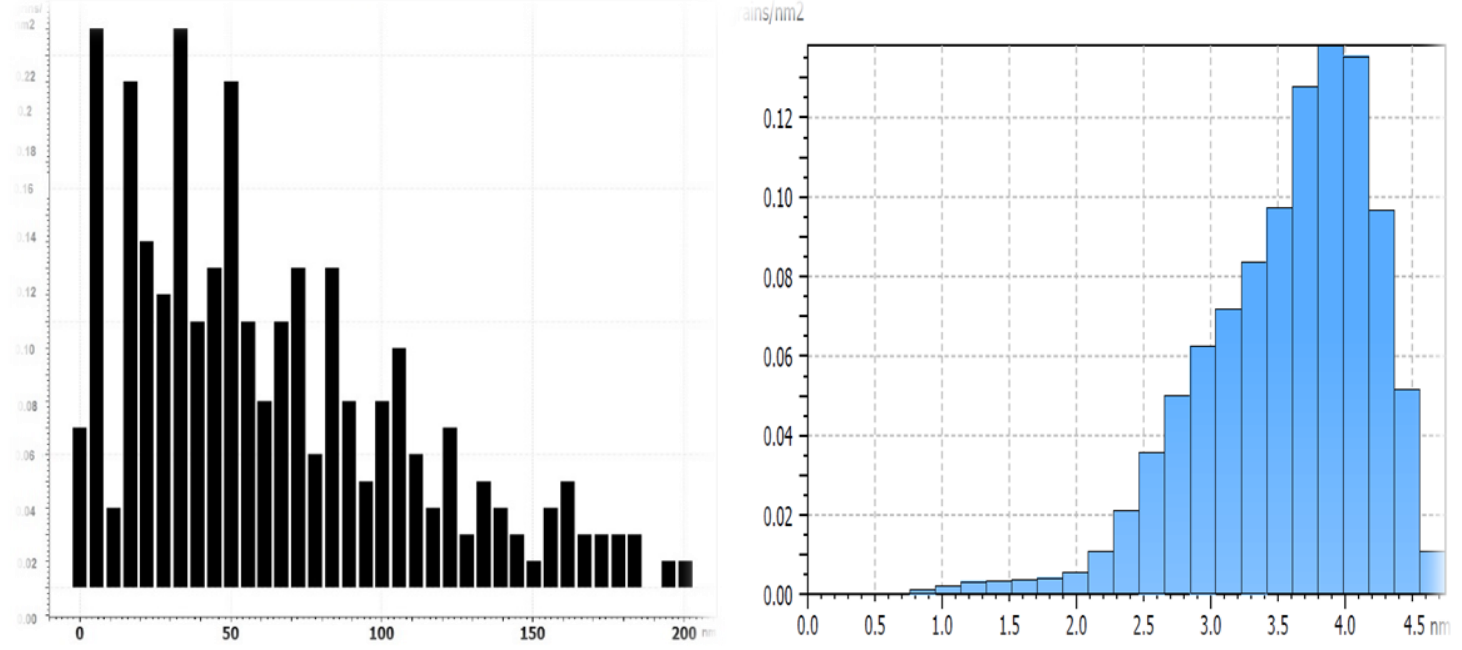

Fig. (6) AFM test for first sample in the left and the second sample in the right. 


$\begin{array}{lll}\text { Open Access } & \text { P- ISSN: 2220-5381 } \\ \text { No. 33, December 2021, pp.17-35 } & \text { E- ISSN: 2710-1096 }\end{array}$

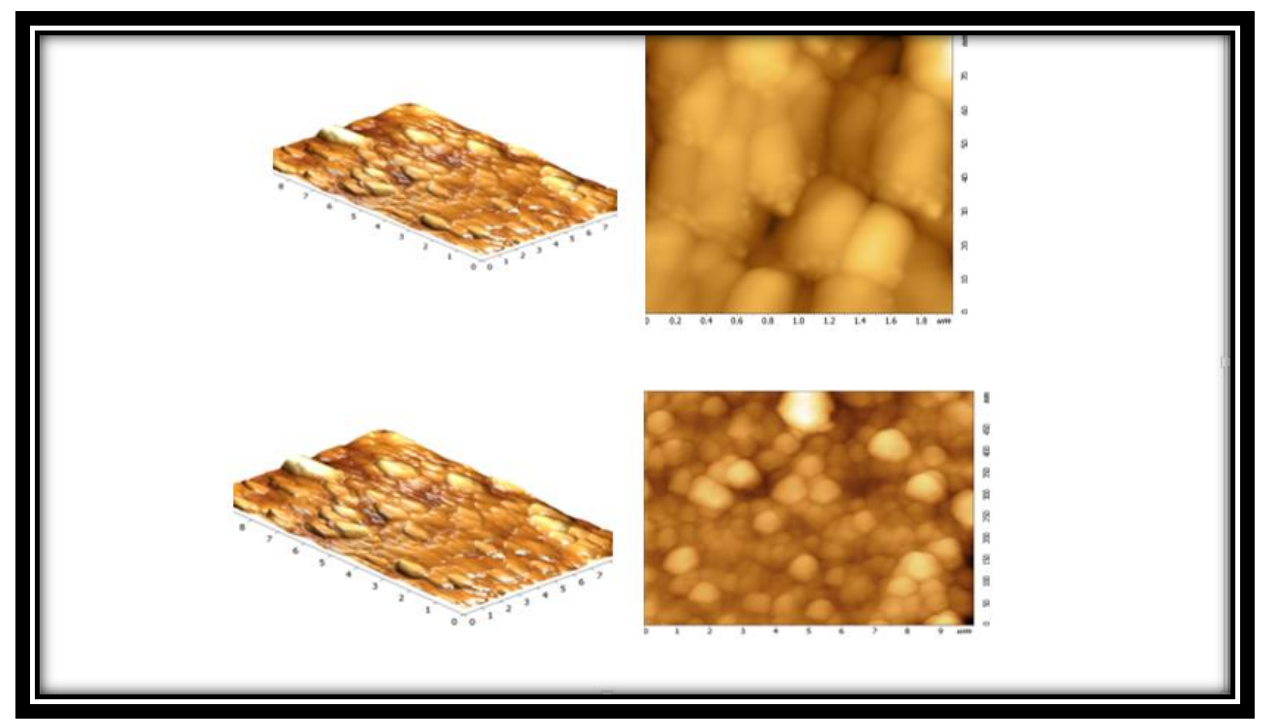

Fig. (7) The pattern of AFM Test for NHL1

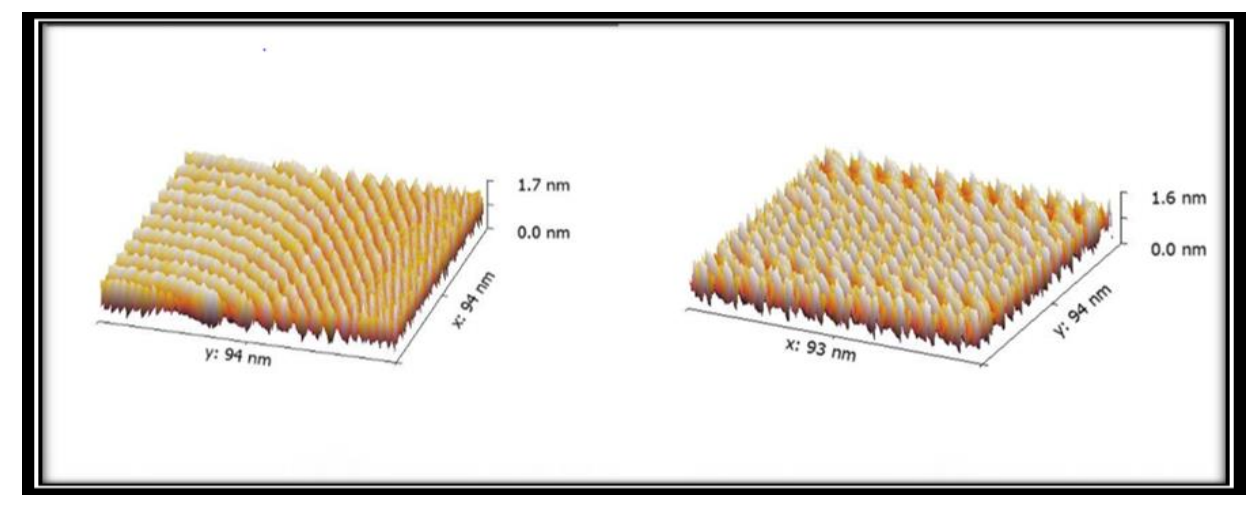

Fig. (8) The pattern AFM Test for NHL2

\subsubsection{X-Ray Diffraction (XRD) Analysis}

The structure for two samples of the prepared Nano hematite is evaluated in this analysis by using X-ray diffraction patterns. The results are then compared with the XRD analysis of standard Nano hematite. Tables (1) and (2) present the results of the XRD analysis of the first sample $(\mathrm{NH} 1<100 \mathrm{~nm})$ and the standard hematite analysis, respectively. The results reveals a similarity between the prepared and standard Nano hematite, which indicated that the formed substance is hematite. The highest Peaks (2, $3,5,6,8$, and 9) of the first sample ( $\mathrm{NH} 1<100 \mathrm{~nm})$ are taken and comparing the results with the standard Hematite in terms of location and height of the corner of each Peak, it 
Open Access

No. 33, December 2021, pp.17-35

is found that there is small amount of non- conformity (an acceptable trial error) in terms of location or elevation of the corner. [15]

Table (2) XRD analysis for standard hematite.

\begin{tabular}{|c|c|c|}
\hline no. peak & 2-Theta & Intensity \\
\hline 1 & 24.138 & 30 \\
\hline 2 & 33.152 & 100 \\
\hline 3 & 35.611 & 70 \\
\hline 4 & 39.276 & 3 \\
\hline 5 & 40.854 & 20 \\
\hline 6 & 43.518 & 3 \\
\hline 7 & 49.479 & 40 \\
\hline 8 & 54.089 & 45 \\
\hline 9 & 56.15 & 1 \\
\hline 10 & 57.428 & 5 \\
\hline 11 & 57.589 & 10 \\
\hline 12 & 62.449 & 30 \\
\hline 13 & 63.989 & 30 \\
\hline
\end{tabular}

Table (3) XRD analysis for NHL1

\begin{tabular}{|c|c|c|}
\hline no.peak & 2-Theta & Intensity \\
\hline 1 & 24.296 & 28.2 \\
\hline 2 & 33.267 & 100 \\
\hline 3 & 35.714 & 88 \\
\hline 4 & 40.991 & 28.7 \\
\hline 5 & 49.537 & 45.8 \\
\hline 6 & 54.187 & 45.8 \\
\hline 7 & 57.633 & 8.3 \\
\hline 8 & 62.53 & 33.3 \\
\hline 9 & 64.087 & 43.1 \\
\hline 10 & 72.011 & 13.9 \\
\hline 11 & 75.6 & 8.8 \\
\hline 12 & 85.031 & 11.1 \\
\hline 13 & 88.724 & 7.4 \\
\hline
\end{tabular}


Also, reading the results of the XRD test for the second sample $(\mathrm{NH} 2<5 \mathrm{~nm})$ by taking the highest peaks $(2,3,7,8,12,13)$ and comparing them with XRD analysis of the standard hematite as shown in the Table (4).

The small difference in the position or height of angle may indicate the presence of some impurities, from not washing the material well before drying, or perhaps an error in the method of drying, or a decrease or increase in the time of calcination.

Table (4) XRD analysis for NHL2

\begin{tabular}{|c|c|c|}
\hline no.peak & 2-Theta & Intensity \\
\hline 1 & 24.138 & 30 \\
\hline 2 & 33.158 & 100 \\
\hline 3 & 35.633 & 78 \\
\hline 4 & 39.276 & 3 \\
\hline 5 & 40.854 & 20 \\
\hline 6 & 43.518 & 3 \\
\hline 7 & 49.445 & 36 \\
\hline 8 & 54.066 & 46 \\
\hline 9 & 56.15 & 1 \\
\hline 10 & 57.428 & 5 \\
\hline 11 & 57.589 & 10 \\
\hline 12 & 62.439 & 30 \\
\hline 13 & 64.007 & 30 \\
\hline
\end{tabular}

\subsection{Drilling Fluids Formulation}

A water-based drilling mud sample was prepared from (350cc water + 22.5gm Bentonite) and placed in a closed cup, and then the cup was placed in the water bath for 24 hours, at a temperature of $25^{\circ} \mathrm{C}$. After 24 hours, the properties of the drilling mud were measured, [9]. Table (6) presents the measured properties of the blank drilling mud.

\subsection{Performance of Nano hematite Drilling Muds}

The aim of the chemical additives is to control the main properties and rheological properties of the drilling mud. Nano-Hematite $\left(\mathrm{Fe}_{2} \mathrm{O}_{3}\right)$ was chosen as an additive for 
weighting drilling mud, as it is one of the materials that is characterized by the weight of its particles, because it is composed of heavy iron particles. The first phase of this research is study the influence of the two chemically prepared models of Nano-hematite on mud properties. While the second phase is making a performance comparison between synthesis, commercial Nano-hematite material, and the commercial Barite $\left(\mathrm{BaSO}_{4}\right)$ materials in term of drilling mud properties.

\subsubsection{Nano hematite (prepared in the lab) Fe2O3 additive}

In this mode of testing, the blank mud was treated with two modules. The first (mud 2) was added 18 gm. of (NHL1 <100nm) and the second (mud 3) was treated with $18 \mathrm{gm}$. of (NHL2 $<\mathbf{5 n m}$ ) as shown in Table (5). The two models were then left for 24 hours inside the water bath at $25^{\circ} \mathrm{C}$. After 24 hours, the laboratory tests were performed.

Table (5) Composition of mud 2and mud 3.

\begin{tabular}{|c|c|c|c|c|}
\hline Composition & & Mud 1 & Mud 2 & Mud 3 \\
\hline Distilled Water & $\mathrm{mL}$ & 350 & 350 & 350 \\
\hline Bentonite & $\mathrm{gr}$ & 22.5 & 22.5 & 22.5 \\
\hline Nano Hematite 1 & $\mathrm{gr}$ & - & 18 & - \\
\hline Nano Hematite 2 & gr & - & - & 18 \\
\hline
\end{tabular}

Table (6) Properties of Blank mud and treated Nano hematite muds.

\begin{tabular}{|c|c|c|c|c|}
\hline $\begin{array}{c}\text { Mud Properties @ Room } \\
\text { Temperature }\end{array}$ & Unit & MUD1 & MUD 2 & MUD 3 \\
\hline$\Theta 600$ & & 40 & 65 & 65 \\
\hline$\Theta 300$ & & 39 & 59 & 61 \\
\hline PV & $\mathrm{cP}$ & 1 & 6 & 4 \\
\hline YP & $1 \mathrm{~b} / 100 \mathrm{ft} 2$ & 38 & 53 & 57 \\
\hline$\Theta 200$ & - & 38 & 56 & 58 \\
\hline$\Theta 100$ & - & 34 & 52 & 56 \\
\hline$\Theta 6$ & - & 33 & 46 & 50 \\
\hline
\end{tabular}


Open Access

No. 33, December 2021, pp.17-35

P- ISSN: 2220-5381

E- ISSN: 2710-1096

\begin{tabular}{|c|c|c|c|c|}
\hline$\Theta 3$ & - & 33 & 46 & 50 \\
\hline GEL STRENGTH (Gel 10s) & lb/100ft2 & 30 & 46 & 50 \\
\hline GEL STRENGTH (Gel 10min) & lb/100ft2 & 35 & 49 & 52 \\
\hline PH@ 25 ${ }^{\circ} \mathrm{C}$ & - & 9.07 & 9.51 & 9.51 \\
\hline API Filtrate & cc/30 min & 13 & 10.6 & 10.4 \\
\hline Filter Cake Thickness & in/32 & $4 / 32^{`}$ & $4 / 32^{\prime}$ & $4 / 32^{”}$ \\
\hline Density @ 25 ${ }^{\circ} \mathrm{C}$ & Pcf & 64 & 67 & 67 \\
\hline Torque Reading by lubricity Meter & - & 55.8 & 55.1 & 55.1 \\
\hline Lubricity Factor & - & 0.5317 & 0.5250 & 0.5250 \\
\hline
\end{tabular}

Table (6) summarized the results of testing these muds .As for weighting property, the muds were densified simultaneously with inclusion of (NHL1 <100nm) and (NHL2 $<\mathbf{5 n m}$ ) at the same concentrations compare to the blank mud. There was an increase in the density with the addition of Nano hematite, and the increase was equal for both models. Through above discussion, it's observed that the size of the particles had no effect on the density, the densities were equal for both models.

As for rheological properties, it is observed the second model has better rheological properties than the first model, due to the smaller particles of the second model.

As for fluid loss property, there is a decrease in fluid loss volume after adding Nano hematite particles, but the thickness of mud cake remains constant for both models.

In addition, there is a slight decrease in torque readings for both samples when compared with blank mud, which means that there is a decrease in the oiliness in the mud and thus a decrease in the rate of friction. 
Table (7) Static Sag Evaluation

\begin{tabular}{|c|c|c|c|}
\hline Properties & Mud1 & Mud2 & Mud3 \\
\hline Density @25C & 64 & 67 & 67 \\
\hline $\begin{array}{c}\text { Density@25C (Measuring Density } \\
\text { after storage 1 hours mud @ 35C in } \\
\text { oven statically) }\end{array}$ & 64 & 67 & 67 \\
\hline $\begin{array}{c}\text { Density @25C (Measuring Density } \\
\text { after storage 1 hours mud @ 65C in } \\
\text { oven statically) }\end{array}$ & 64 & 66 & 65 \\
\hline $\begin{array}{c}\text { Density @25C (Measuring Density } \\
\text { after storage 1 hours mud @ 85C in } \\
\text { oven statically) }\end{array}$ & 64 & 65 & \\
\hline
\end{tabular}

As for sagging tendency of the two prepared Nano hematite, Table (7) shows that the effect of sagging with increasing temperature, when the temperature increased, the intensity decreased. The decrease values were similar for both models.

Table (8) Magnetic Properties

\begin{tabular}{|c|c|}
\hline Sample & \%Percent \\
\hline Nano Hematite 1 & 0 \\
\hline Nano Hematite 2 & $100 \%$ \\
\hline Bentonite & 0 \\
\hline
\end{tabular}

Through the results shown in the above table 8 for the magnetic ratio of both models, notice that the first model has $0 \%$ of magnetism. The second model, the percentage of magnetism is $100 \%$, which means that the impurities in the second model are mostly magnetizable and may have a magnetic property.

Whereas, the magnetic property depends on the way the particles assemble, and on the source of the ore and its impurities. [4] Also, the temperature may have a relationship in the loss of the first sample the magnetic property, as the heating causes the particles to move in random directions at high speed, which causes a loss of magnetism. [10] 
About the magnetic property, it's found the second model is not acceptable as additive for field drilling fluid. Because the magnetic property causes many problems, as it causes distortion in the readings of the logs, and the particles are also attracted towards the minerals below the well. Thus, the first model is considered the best. The first model will be adopted in this study to make the remaining comparisons.

\section{Conclusion}

1. When preparing two models in the laboratory, and conducting XRD, AFM analysis, for both models, both models were Nano size.

2. The second sample, NHL2, has much smaller size, due to the presence of CTAB, which helped in reducing the surface tension, but it has high magnetic property. This method was neglected due to high magnetic properties of the resulting material.

3. After comparing the rheological properties of the two samples, it was observed that the density of drilling mud was not affected by particle size. Both models have the same weight properties.

4. The second sample has better rheological properties than the first sample, due to the smaller particles of the second model.

5. Considered the first sample least expensive in chemical preparation compare with second sample. 


\section{$\underline{\text { References }}$}

[1] MI, Drilling fluid manual UAS: s.n, 1996.

[2] Abdelmjeed Mohamed, Saad Al-Afnan, Salaheldin Elkatatny, and Ibnelwaleed Hussein, (Prevention of Barite Sag in Water-Based Drilling Fluids by A Urea-Based Additive for Drilling Deep Formations), 2020.

[3] J. P. Robert et al., (Effects of Material Weight Type and Clay Formation on Penetration Rate Using Reflective Oil Systems), in: SPE Annual Technical Conference, San Antonio, Texas, USA, 1981.

[4] Tovar, J., Rodríguez, Z., Quiroga, F., Greaves, R., Melendez, H., Arocha, J., \& Hebert, M. ORIMATITA®. An improved hematite for drilling fluids. In Latin American and Caribbean Petroleum Engineering Conference. Society of Petroleum Engineers, 1999.

[5] S. D. Ukeles and B. Grinbaum, (Drilling Fluids), in: Kirk-Othmer Encyclopedia of Chemical Technology, 5th ed., Wiley, Weinheim, Germany, 2000.

[6] Zhihong Jinga,b, Dongzhan Hana, Shihua Wua, ( Morphological evolution of hematite nanoparticles with and without surfactant by hydrothermal method), 2004.

[7] M. Mohapatra a, T. Padhi a, S. Anand a \& B.K. Mishra a a Institute of Minerals and Materials Technology, Bhubaneswar, (CTAB mediated Mg-doped Nano Fe2O3: synthesis, characterization, and fluoride adsorption behavior), 2012.

[8] Jeffrey Yue, Xuchuan Jiang*, Qinghua Zeng, Aibing Yu, (Experimental and numerical study of cetyltrimethylammonium bromide (CTAB)-directed synthesis of goethite nanorods), 2010.

[9] Darley, H. \& Gray, G. R, (Composition and Properties of Drilling and Completion Fluids fifth edition. USA: Gulf Professional Publishing, 1988. 
[10] Lesleis Nagy, Wyn Williams, Adrian R. Muxworthy, Karl Fabian, Trevor P. Almeida, Pádraig Ó Conbhuí, Valera P. Shcherbakov, (Stability of equidimensional pseudo-single-domain magnetite over billion-year timescales), 2017.

[11] Ibrahim S. Ahmed 1, Mostafa Y. Nassar2, N.Hassan3, Michael B. Azmy3, (Synthesis and photocatalytic activity of nano-sized iron oxides), 2014.

[12] $\quad$ https://www.fann.com/fann/products/supplies-and-reagents/lab-equipment-N supplies/blenders-and-

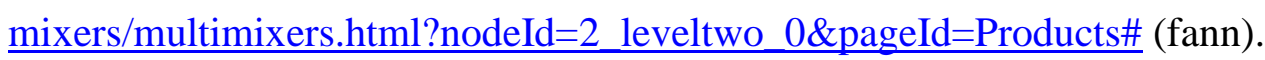

[13] http://www.ofite.com/news/testing-the-lubricating-properties-of-drilling-fluids, (OFI Testing Equipment, Inc., 2017).

[14] Vanhanen, J., Mikkilä, J., Lehtipalo, K., Sipilä, M., Manninen, H. E., Siivola, E., ... \& Kulmala, M ,.Particle size magnifier for nano-CN detection. Aerosol Science and Technology, 45(4), 533-542, 2014.

[15] Speakman, S. A. Introduction to x-ray powder diffraction data analysis. Center for Materials Science and Engineering at MIT, 2013. 